\title{
SAP FOR SURVIVAL
}

\section{DONALD F. HOOPER, Box 40, Somme, Saskatchewan. SOE 1N0}

The storm that came on the night of 30 April and continued most of the morning on 1 May dumped about $14 \mathrm{~cm}$ of snow in the Somme district. This made quite a hardship for the many species of insecteating birds back from their winter homes in the south.

On the morning of 2 May there were many birds around the Manitoba Maples at the end of the garden where there was a patch of bare ground under the shelter of the spreading limbs. Several robins and Rusty Blackbirds were gathered together and Fox Sparrows were scratching back the leaves to uncover insects. A Hermit Thrush pulled out a large earthworm.

A male Yellow-rumped Warbler flitted through the maple branches close to the bottom of the trees. It would flush small moths from the tips of the branches out into the snow and catch them as they were paralysed by the cold. He then went to a Yellow-bellied Sapsucker hole in the bark of a maple trunk and fed on the sap. The sapsucker kept very busy chasing the warbler which retumed again and again to the same hole to rob the sweet contents. The sap run was in several trees and the woodpecker went from tree to tree to feed on the sap as the holes filled up.

It is interesting to see a warbler feed on sap as a supplement because of a shortage of insects after a snowstorm. This probably happens more than we think for on 4 May a neighbour of mine saw a Yellow-rumped Warbler and a junco feeding on maple sap that was flowing from a crotch in a branch.

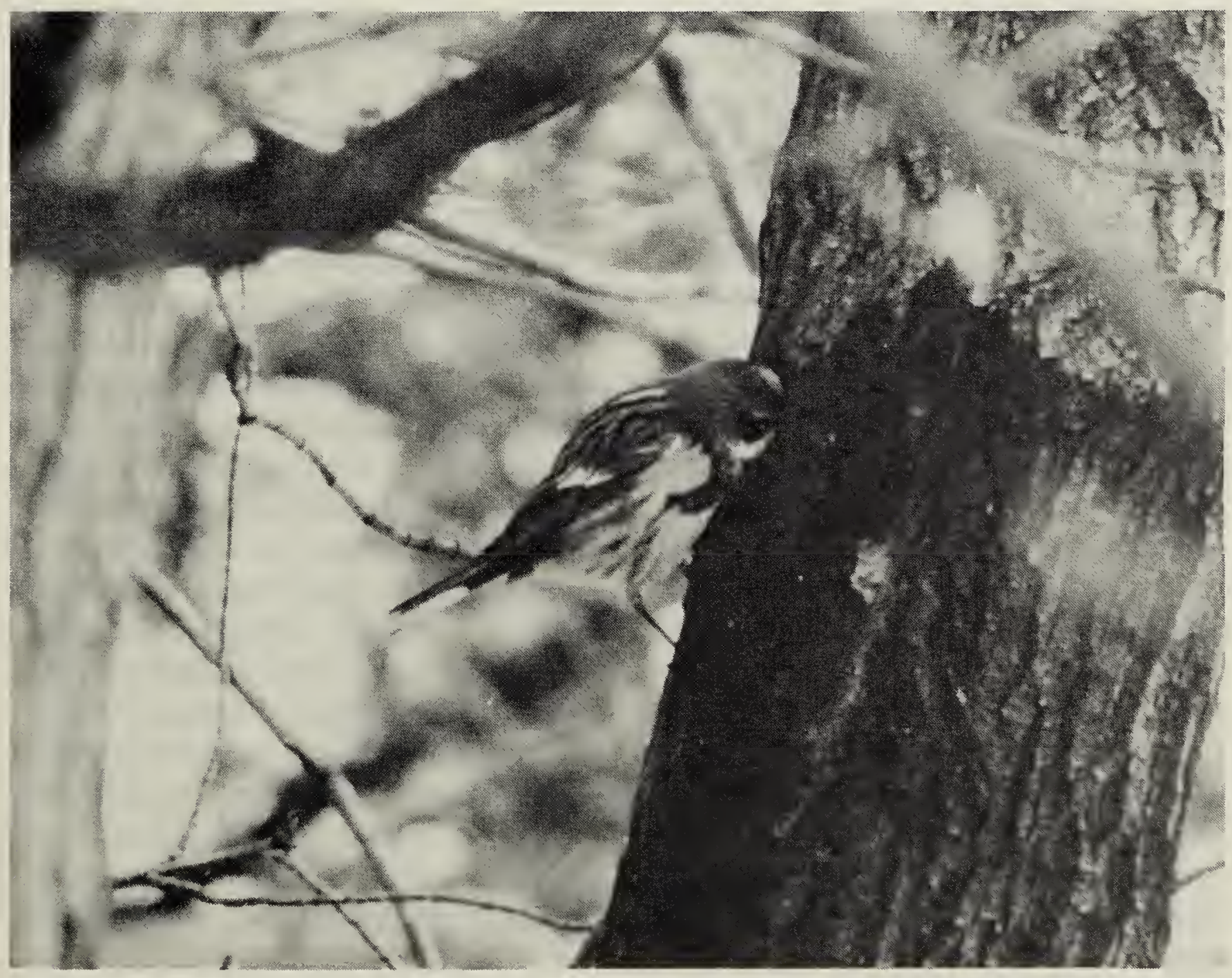

